\title{
ENCEH: KARYA TARI SEBAGAI EKSPRESI UPACARA RITUAL DI MAKAM RAJA-RAJA IMOGIRI
}

\author{
Hendy Hardiawan \\ Program Pascasarjana, Institut Seni Indonesia, Yogyakarta, Indonesia \\ Email: hendyhardiawan7@gmail.com
}

\section{RINGKASAN}

Karya tari yang berjudul Encèh terinspirasi dari nama upacara ritual yang ada di Makam Raja-Raja Mataram di Imogiri yaitu Nguras Encèh. Karya ini bercerita tentang latar belakang dan proses upacara Nguras Enceh, yang diawali dari awal ritual sampai akhir upacara Nguras Encèh. Upacara ini diadakan setiap bulan Sura. Nguras Encèh merupakan simbolisasi pembersihan diri dari segala sesuatu yang buruk dalam diri manusia. Dalam hal ini sesuatu yang buruk digambarkan oleh sosok Bethara Kala. Air Encèh dipercaya bertuah dan berguna untuk membersihkan "hati" yang diselimuti iri, dengki, benci, murka dan berbagai emosi negatif. Lebih dari itu air dari Encèh dipercaya mampu menyembuhkan berbagai macam penyakit.

Kata kunci : Encèh, Nguras Encèh, Bethara Kala, Mataram

\section{ABSTRACT}

The title of the dance is Encèh. This title is taken from a ritual ceremony in the Grave of Mataram Kings at Imogiri, named Nguras Encèh. The dance tells the story of the ceremony from the very beginning of the background and the process itself. The ceremony is held every Sura month (Sura is a Javanese month). Nguras Encèh symbolized the purification from anything bad from human soul. In this dance, the bad thing conceived by Bathara Kala. The water from the Encèh believed as a cure for the heart with any negative emotions such as jealousy, hatred, and anger or wrath. Indeed, the water of the Encèh believed can cure any diseases.

Keywords: Encèh, Nguras Encèh, Bathara Kala, Mataram 


\section{PENDAHULUAN}

Karya tari ini mengangkat salah satu upacara ritual tradisi di Yogyakarta, tepatnya upacara adat Nguras Encèh di kompleks Makam Raja-Raja Mataram di Imogiri, Bantul. Nguras Encèh merupakan upacara ritual yang dilaksanakan setiap tahun sekali pada bulan Sura di hari Jumat Kliwon di kompleks Makam Raja-Raja Mataram di Imogiri. Kata Encèh dalam bahasa Jawa berarti gentong, yaitu nama benda utama yang ada dalam upacara ritual Nguras Encèh. Upacara ini merupakan upacara ritual pembersihan empat buah encèh (gentong tempat menampung air) yang konon merupakan buah tangan dari Kerajaan Siam, Kerajaan Palembang, Kerajaan Aceh, dan Kerajaan Turki yang diberikan kepada Sultan Agung Hanyakra Kusuma. Upacara ini dilakukan dengan menguras encèh-encèh tersebut dengan cara dituangkan air suci ke dalam encèh hingga meluap. Upacara ini melambangkan pembersihan diri manusia dari keburukan dan kenistaan. Masyarakat yang kerap kali menghadiri upacara ini percaya bahwa air luapan encèh tersebut sebagai berkah dan mampu menyembuhkan berbagai penyakit.

Upacara ritual Nguras Enceh menjadi sumber inspirasi dalam pembuatan karya tari ini. Pemilihan objek upacara ritual ini dikarenakan penata tari sering menyaksikan upacara ritual tersebut dan menjadi bagian dari masyarakat Imogiri sebagai penyangga budaya ini. Melalui karya tari ini penata tari ingin menginformasikan lebih dalam tentang upacara ritual Nguras Encèh.

\section{PEMBAHASAN}

\section{A. Kerangka dasar Pemikiran}

1. Rangsang awal

Rangsang adalah sesuatu yang dapat membangkitkan akal dan pikiran untuk dapat melakukan aktivitas. Rangsang bagi komposisi tari dapat berupa auditif, visual, gagasan, rabaan dan kinestetik ${ }^{1}$. Rangsang awal karya ini adalah rangsang visual dari melihat langsung upacara ritual Nguras Encèh di Makam Raja-Raja Mataram di Imogiri. Upacara ritual ini yang menjadi sumber inspirasi dalam pembuatan karya tari ini, pemilihan objek upacara ritual ini karena bagi penata tari upacara ritual ini menarik, selain itu juga penata tari sering menyaksikan upacara ritual tersebut.

\section{Tema Tari}

Tema tari dapat dipahami sebagai pokok arti permasalahan yang mengandung sesuatu

\footnotetext{
1 Jacqueline Smith. 1985. Dance Composition: A Practical Guide for Teachers, terj. Ben Suharto, Komposisi Tari: Sebuah Petunjuk Praktis Bagi Guru, Yogyakarta: Ikalasti, p.20.
} 


\section{JOGED}

ISSN: 1858-3989

maksud atau motivasi tertentu. ${ }^{2}$ Pemilihan suatu tema bertujuan untuk memberikan batasan kepada penata untuk tetap fokus pada esensi garapan tari, sehingga proses penciptaan tidak keluar jauh dari tema yang diinginkan. Tema karya tari ini adalah kebersihan, yang dilakukan pada upacara Nguras Encèh di Makam Raja-Raja Mataram Imogiri yang bertujuan untuk membersihkan segala sesuatu yang buruk dalam diri manusia.

\section{Judul Tari}

Karya tari ini berjudul "Encèh". Kata encèh berarti gentong, yang diambil dari nama upacara ritual yaitu Nguras Encèh. Judul tersebut merupakan suatu identitas yang dibutuhkan dan berhubungan erat dengan karya yang ditampilkan.

\section{Tipe Tari}

\section{Menurut buku Dance Composition $A$} Practical Guide For Teacher terjemahan Ben Suharto, tipe tari terdiri dari tari murni, tari studi, tari abstrak, tari liris, tari dramatik, dramatari, dan tari komik. Karya tari ini menggunakan tipe tari dramatik yang memusatkan perhatian pada sebuah kejadian atau suasana, tanpa menggelar cerita dan tanpa penokohan. ${ }^{3}$ Suasana dan kronologis

2 Y. Sumandiyo Hadi. Koreografi BentukTeknik-Isi. Yogyakrta: Cipta Media. 2011. p. 59

3 Jacqueline Smith, 1985.Dance Composition: A Practical Guide for Teachers, terj. ritual Nguras Encèh menjadi hal penting untuk disampaikan kepada penonton, sehingga penonton dapat merasakan suasana yang diinginkan oleh penata tari.

5. Mode Penyajian

Mode penyajian karya tari merupakan salah satu cara menyampaikan atau mengungkapkan maksud dan makna secara langsung dan tidak langsung. Mode penyajian yang digunakan dalam karya tari adalah simbolis representasional. Menggunakan gerak-gerak simbolis yang memiliki makna tertentu yang disampaikan kepada penonton melalui aspek ruang dan waktu yang juga didukung oleh properti dan setting panggung. Representasional dalam karya ini, memiliki alur cerita yang diuraikan secara detail untuk membantu daya serap penonton pada karya yang disajikan. Representasional juga terlihat dari karya ini dengan properti encèh yang ditampilkan menyerupai bentuk aslinya.

6. Gerak Tari

Gerak dalam sebuah karya tari merupakan media utama untuk menyampaikan maksud yang ingin diungkapkan kepada penonton. Penata tari yang berlatar belakang dari tari klasik gaya Yogyakarta dan tari garapan baru, menggabungkan kedua latar belakang

Ben Suharto, KomposisiTari:Sebuah Petunjuk Praktis bagi Guru, Yogyakarta: Ikalasti, pp. 24-27. 
tersebut menjadi satu tanpa menghilangkan esensi dari gerak tari gaya Yogyakarta. Gerak yang digunakan merupakan dasar gerak tari klasik putra gagah gaya Yogyakarta, gagah lugu perwujudan gerak tari yang gagah, sederhana, dan mantap. Aliran gerak mantap dan pasti mencerminkan kekuatan dan sikap jiwa yang bersahaja. ${ }^{4}$ Motif gerak inilah yang dikembangkan berdasarkan aspek ruang dan waktu, yang kemudian disusun menjadi sebuah karya tari.

\section{Penari (Jumlah dan Jenis Kelamin)}

Penari dalam karya tari Encèh berjumlah enam orang penari putra. Penata memilih penari yang sudah mempunyai kemampuan menari tari klasik gagah gaya Yogyakarta. Postur tubuh tidak menjadi syarat utama, karena yang dipentingkan rasa dan kesatuan menari dan bukan postur tubuh, karena di dalam karya tari ini tidak ada penokohan. Alasan dipilihnya penari putra dikarenakan ketertarikan penata terhadap sosok abdi dalem yang merupakan pelaksana dari upacara Nguras Encèh tersebut.

\section{Musik Tari}

Dalam setiap penyajian karya tari tidak pernah terlepas dari musik. Musik tari berfungsi selain sebagai ilustrasi pendukung

4 Freed WIBowo, Tari Klasik Gaya Yogyakarta. Yogyakarta: Yayasan Bentang Budaya, 2002, p.16 pertunjukan, juga sebagai pengiring, partner dan pengikat. Musik mempunyai pengaruh besar dalam sebuah karya tari. Melalui musik mampu dibangun suasana yang diinginkan. Karya tari ini menggunakan instrumen gamelan Jawa yang digarap melalui music instrument digital interface (midi). Alat yang digunakan seperti kendang, rebab, siter, bonang, demung, saron, gambang, kenong, kempul, gong. Suara dari instrumen gamelan akan membawa penonton berada di dalam suasana tradisi Yogyakarta. Penambahan alat musik diatonis yang ada di program musik digital seperti cymbal, drum, biola, piano. Alat musik tersebut dikolaborasikan dengan gamelan, yang akan membangun suasana magis pada karya tari ini.

\section{Ruang Pertunjukan}

Ruang pertunjukan pada karya ini adalah proscenium stage Jurusan Tari Institut Seni Indonesia Yogyakarta, dengan mempertimbangkan aspek-aspek koreografi dalam karya tari ini. Panggung proscenium merupakan panggung dengan satu arah penonton yaitu di bagian depan, panggung ini berada di dalam gedung tertutup. Ruang penonton atau auditorium sengaja dipisah dengan panggung, dengan pengaturan lantai yang berundak meninggi ke belakang bahkan masih terdapat bagian balcony 


\section{JOGED}

ISSN: 1858-3989

sebagai warisan arsitektur Yunani kuno ${ }^{5}$

Demi sebuah kenyamanan bagi penonton agar dapat menikmati pertunjukan dengan sempurna tanpa terhalang penonton yang ada di depannya.

\section{Tata Cahaya}

Dalam sebuah karya tari adanya tata cahaya sangat mendukung pertunjukan karena dapat membantu memberikan kesan ruang yang lebih jelas ketika berada pada posisi titik lemah di panggung, dan juga menjadi pendukung suasana dengan warna pencahayaan yang diberikan. Upacara nguras encèh tidak menggunakan pencahayaan karena upacara tersebut dilakukan pagi hari. Dalam karya tari ini menggunakan lampu modern menggunakan aliran listrik seperti fresnel spotlight, ellipsoidal, par 64, dan zoom light. Lighting yang digunakan dalam karya ini antara lain: pada adegan introduksi, lampu yang digunakan adalah jenis fresnels dengan dominan warna biru, kuning, dan hijau. Pemilihan warna ini dipertimbangkan dari isi adegan yang disampaikan yaitu penggambaran kebesaran kerajaan-kerajaan yang memberi encèh kepada Sultan Agung Hanyakra Kusuma. Pada adegan 1 menggunakan lampu jenis fresnels dan parlamp menggunakan warna kuning, hijau,

5 Hendro Martono. Ruang Pertunjukan dan Berkesenian. Yogyakarta : Cipta Media, 2012, p.38 biru, merah. Warna-warna tersebut membantu membangun suasana tegas, kuat, dan keras yang akan mendominasi gerakan pada adegan ini. Adegan 2 menggunakan lampu jenis fresnels dan par-lamp dengan warna merah. Warna merah akan membantu membangun suasana keras dan kesan kotor pada adegan yang akan di sajikan di adegan ini. Adegan 3 menggunakan lampu jenis spotlight, fresnels, dan par-lamp dengan menggunakan warna hijau untuk membangun suasana damai.

\section{Rias Busana}

Tata rias dan busana merupakan salah satu aspek terpenting dalam suatu pertunjukan, khususnya tari. Rias dan busana memiliki fungsi dapat mengubah wajah, baik yang berkarakter maupun tidak. Dalam karya tari ini semua penari menggunakan rias putra gagah, sedangkan busana yang digunakan adalah memakai celana pendek sepanjang lutut, jarik sapit urang, setagen, kamus timang, dan memakai aksesoris kalung dan kelat bahu berbahan dasar batok kelapa, warna kostum karya ini berwarna coklat. 


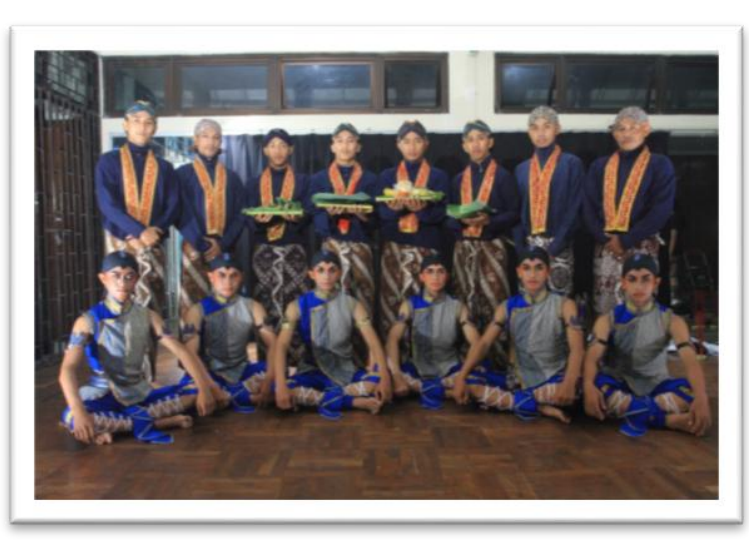

Gambar 1: Kostum tari (Dokumentasi Joe, 2015)

\section{Properti Tari}

Properti yang digunakan dalam karya ini adalah batok kelapa yang dipasang di kedua pergelangan tangan penari. Batok ini diisi dengan biji kedelai agar menghasilkan bunyi yang dapat berfungsi menjadi musik internal. Properti lain yang digunakan adalah siwur sebagai alat untuk menuangkan air ke dalam encèh. Properti tari yang terakhir adalah payung motha sebagai simbol kebesaran keempat kerajaan yang memberi encèh-encèh yang ada di Makam Raja-Raja Mataram di Imogiri.

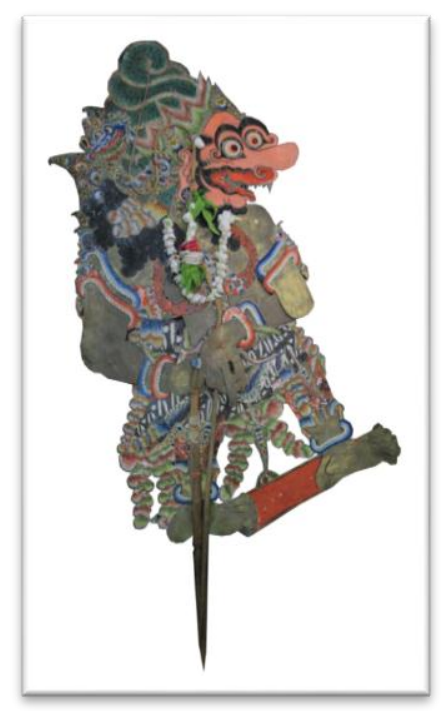

Gambar 2:

Properti wayang

(Dok. Joe, 2015)
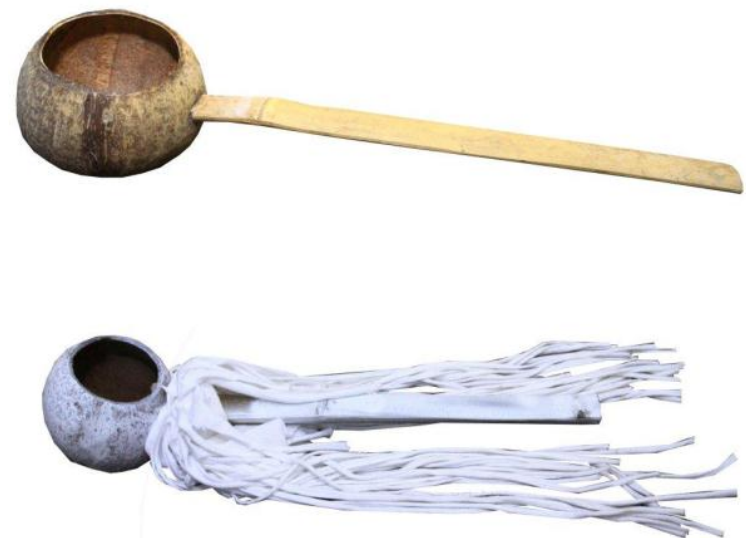

Gambar 3: Properti siwur(Dok, Joe, 2015)

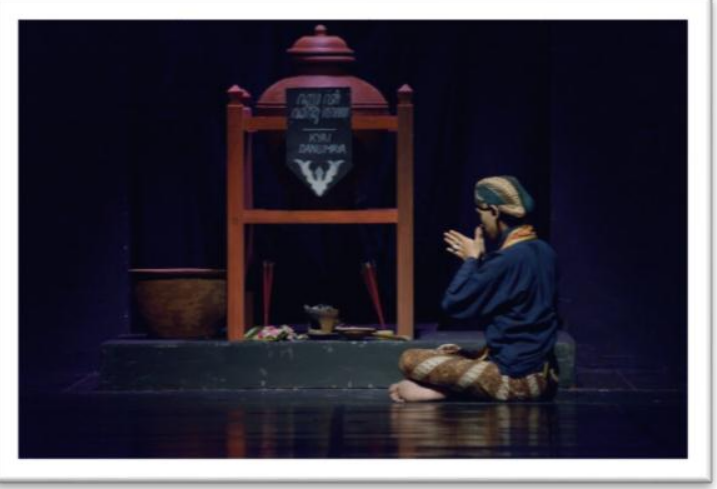

Gambar 4: Properti Encèh (Dok. Budi, 2015)

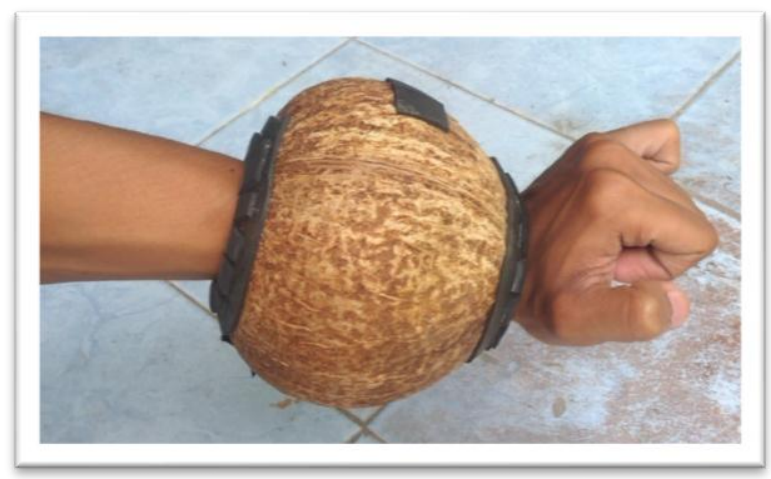

Gambar 5: Properti Batok tangan (Dok. Hendy,

$$
\text { 2014) }
$$

\section{B. Urutan Penyajian}

1. Introduksi

Adegan ini menghadirkan satu orang penari yang menggambarkan seorang abdi dalem yang melakukan ritual Nguras Encèh. 


\section{JOGED}

ISSN: 1858-3989

Penari membaca doa kemudian mengambil air dari pengaron untuk dituangkan ke dalam encèh sebanyak tiga kali.

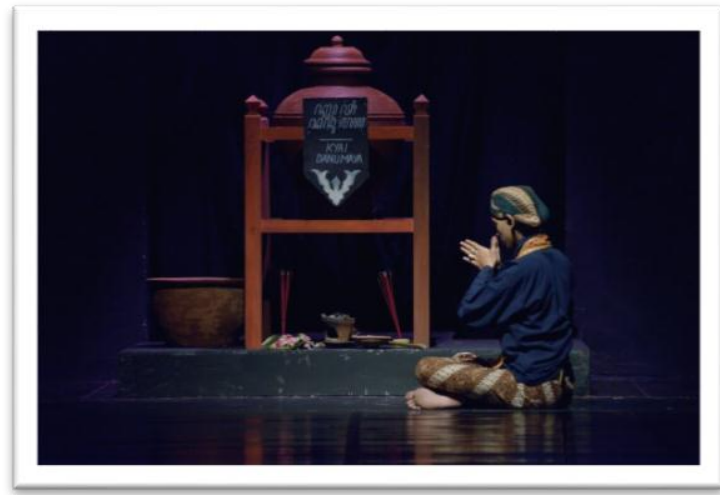

Gambar 6: Adegan Introduksi (Dok. Joe, 2015)

\section{Adegan 1}

Menggambarkan kebesaran keempat kerajaan yang memberikan encèh yaitu kerajaan Siam, Palembang, Aceh, dan Turki. Kebesaran kerajaan-kerajaan tersebut dilambangkan dengan payung motha yang menjadi properti empat orang penari. Dalam adegan ini penata menonjolkan sosok Sultan Agung Hanyakra Kusuma sebagai seorang raja yang disegani.

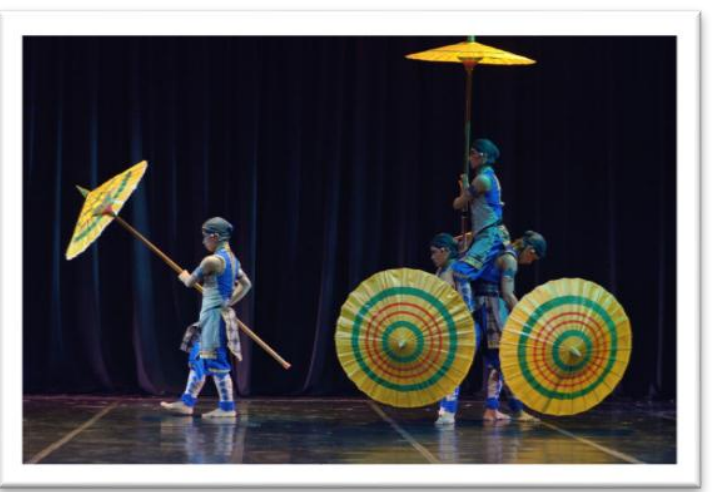

Gambar 7: Adgan 1 (Dok. Budi, 2015)

\section{Adegan 2}

Menggambarkan prosesi nguras siwur. Adegan ini menghadirkan satu orang penari yang membawa dua buah siwur dan disusul empat orang penari lain yang menggunakan properti batok pada pergelangan tangan. Akhirnya, keempat penari ini disusul satu orang penari lagi dari side wing sebelah kanan. Setelah keempat penari masuk, ditampilkan tiga orang penari yang melambangkan segitiga kehidupan. Segitiga kehidupan mengingatkan kepada kita bahwa ada dua hubungan yang harus dijaga, yaitu hubungan vertikal dengan Tuhan dan horizontal dengan sesama manusia di mana ketika digabung akan membentuk sebuah segitiga. Sesaat setelah itu, ketiga orang penari masuk dan keluarlah dua orang penari dari side wing sebelah kiri yang menggambarkan keakraban Keraton Kasultanan Yogyakarta dan Keraton Kasunanan Surakarta yang melakukan ritual Nguras Encèh di Makam Raja-Raja Mataram Imogiri. Sebagai akhir dari adegan ini, kelima orang penari menari dengan gerakan rampak. 


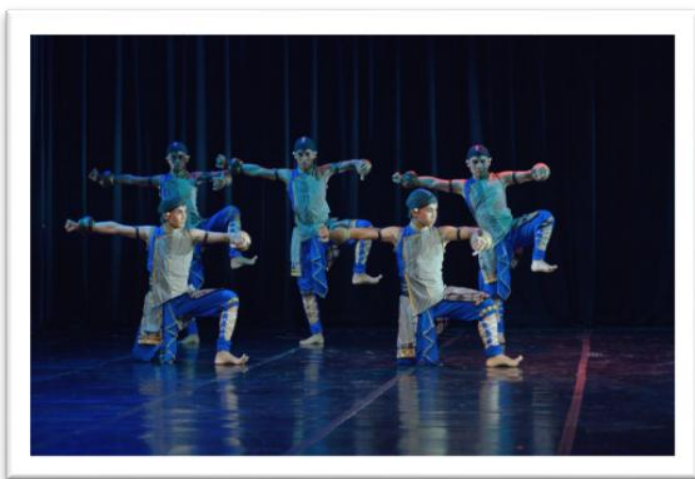

Gambar 8: Adegan 2 (Dok. Budi, 2015)

4. Adegan 3

Menggambarkan kehadiran Bethara Kala sebagai lambang keburukan yang divisualisasikan melalui wayang yang dibawa seorang penari. Kelima orang penari yang lain menggunakan properti siwur yang dibungkus dengan kain warna putih. Adegan ini menghadirkan suasana dramatis di mana keburukan akan kalah dan hilang dengan pembersihan yang dibawa air encèh yang bertuah.

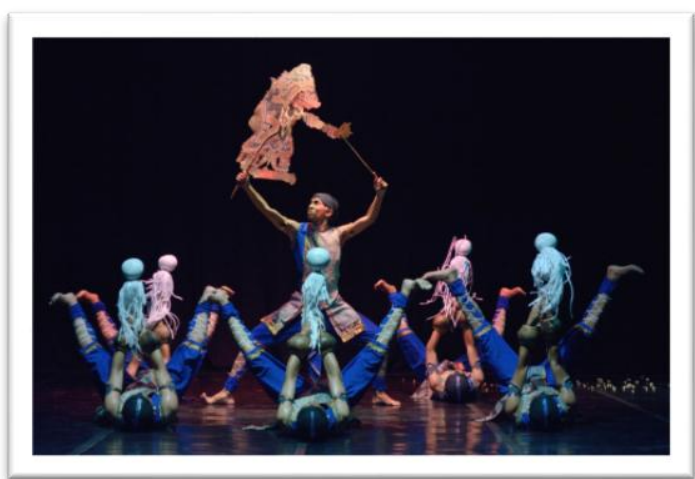

Gambar 9: Adegan 3 (Dok. Budi, 2015)

5. Adegan 4

Menggambarkan hadirnya sembilan orang abdi dalem yang mengenakan busana peranakan. Para abdi dalem ini membawa sajen dan dupa dan melakukan ritual doa hingga akhirnya prosesi Nguras Encèh selesai.

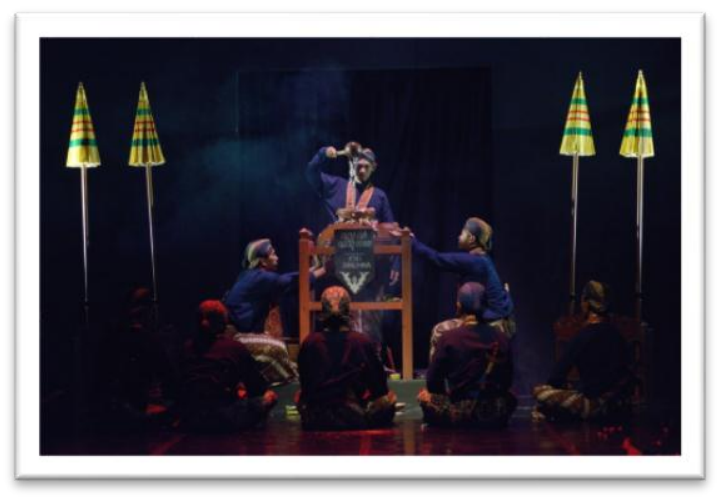

Gambar 10: Adegan 4 (Dok. Budi, 2015)

\section{PENUTUP}

Penciptaan sebuah karya tari memerlukan proses yang panjang dan tidak mudah. Berbagai hal yang kadang tidak dapat diungkapkan secara eksplisit harus tergambar jelas dalam gerak tari. Terlebih jika karya tari yang diangkat merupakan sebuah ritual atau upacara adat yang di dalam benak masyarakat terkesan membosankan dan tidak menarik untuk diikuti. Dalam hal ini seorang penata tari harus dapat melebarkan cakrawala pemikiran dan kreativitasnya untuk mengemas sebuah ritual atau upacara adat menjadi sesuatu yang menarik sekaligus mengedukasi. Inspirasi mengangkat karya ini diawali dengan rangsang visual di mana penata menyaksikan prosesi upacara Nguras Encèh. Berangkat dari rasa ingin tahu mengenai upacara ini, penata merencanakan 
JOGED

ISSN: 1858-3989

dan berkreasi mengemas upacara ritual ini dengan cara yang berbeda dan lebih menarik.

Karya tari Encèh merupakan karya tari kelompok, ditarikan oleh enam orang penari laki-laki. Para penari laki-laki ini merupakan penggambaran pelaku prosesi ritual Nguras Encèh yang pada praktiknya dilakukan oleh laki-laki yaitu abdi dalem Keraton Kasultanan Yogyakarta dan Keraton Kasunanan Surakarta. Materi gerak yang cepat, keras, dan tegas adalah gerak yang mewakili greget ketika upacara ini berlangsung. Gerak tari putra gaya Yogyakarta menjadi ciri khas karya ini karena upacara Nguras Encèh ini dilakukan di kompleks Makam Raja-Raja Mataram Imogiri di Yogyakarta.

\section{DAFTAR SUMBER ACUAN}

A. Sumber Tertulis

Ellfeldt, Lois. 1977.A Primer For Choreographers, terj. Sal Murgiyanto, Pedoman Dasar Penata Tari, Jakarta: Lembaga Pendidikan Kesenian Jakarta.

Hadi, Y. Sumandiyo. 2012. Koreografi Bentuk-Teknik-Isi. Yogyakarta: Cipta Media.

Martono, Hendro. 2008. Sekelumit Ruang Pentas Modern dan Tradisi, Yogyakarta: Cipta Media.
UPACARA RITUAL DI MAKAM RAJA-RAJA IMOGIRI

Martono, Hendro, 2010. Mengenal Tata

Cahaya Seni Pertunjukan. Yogyakarta: Cipta Media.

Meri, La. 1986. Dances Composition the Basic Elements, terj. Soedarsono, Elemen-elemen Dasar Komposisi Tari,Yogyakarta: Akademi Seni Tari Indonesia.

Priadi A, Wahyuni, Nurbudiyono, Nugroho NA. 2007. Upacara Adat yang ada di Wilayah Kabupaten Bantul. Yogyakarta: Sang Surya Grafika

Saptawati N, Setowahyono A. 1995. Sebuah Catatan Tentang Keberadaan Nama Yang Disemayamkan Di Dalam Makam Raja-Raja Di Komplek Pemakaman Imogiri, Kota Gede, Girilaya, Serta Banyusumurup - D.I. Yogyakarta (terj.). Bandung.

Smith, Jacqueline. 1985.Dance Composition: A practical guide for teachers, terj. Ben Suharto, Komposisi Tari: Sebuah petunjuk praktis bagi guru, Yogyakarta: Ikalasti.

Wibowo, Fred. 2002. Tari Kalasik Gaya Yogyakarta. Yogyakarta : Yayasan Bentang Budaya.

B. Narasumber

Ardi Pawoko, umur 49 tahun, abdi dalem keraton Yogyakarta.

Suhardi, umur 49 tahun, profesi pegawai swasta, Alamat: Cempluk, Mangunan, Dlingo, Bantul, Daerah Istimewa Yogyakarta. 